Int. J. Electrochem. Sci., 5 (2010) 88 - 104

International Journal of

ELECTROCHEMICAL

SCIENCE

www.electrochemsci.org

\title{
Molecularly Imprinted Polymer Based PVC-Membrane-Coated Graphite Electrode for the Determination of Metoprolol
}

\author{
Mohammad Saber Tehrani , Mohammad Taghi Vardini, Parviz Abroomand Azar, and Syed waqif \\ Husain \\ Department of chemistry, Science and Research Branch, Islamic Azad University, Tehran, Iran \\ *E-mail: m.sabertehrani@yahoo.com
}

Received: 15 October 2009 / Accepted: 11 January 2010 / Published: 31 January 2010

A PVC membrane based on metoprolol molecularly imprinted polymer (MIP) coated directly on graphite electrode for determination of metoprolol in real sample is described. This potentiometric sensor was designed by dispersing the MIP particles in dioctylphthalate plasticizer as solvent mediator and then embedded in polyvinyl chloride matrix. The electrode exhibits a near Nernstian of $55.4 \pm 1 \mathrm{mV}$ decade $^{-1}$ for metoprolol over a wide concentration range between $2.0 \times 10^{-7}-8.0 \times 10^{-3} \mathrm{M}$ and a detection limit of $1.26 \times 10^{-7} \mathrm{M}$. It has a response time of about 14 seconds and can be used for at least 6 months without any divergence in potential. The proposed electrode can be used in the $\mathrm{pH}$ range of 3.5-10.5 and revealed good selectivities for metoprolol over a wide variety of ions. Finally, the designed sensor was successfully applied as an indicator electrode to determine concentration of metoprolol in tablets, human urine and plasma and the results were compared favorably with those obtained by HPLC method and showed satisfactory agreements with them.

Keywords: Metoprolol, Ion-selective electrode, Molecularly imprinted polymer, PVC-membrane, Coated graphite

\section{INTRODUCTION}

Metoprolol is a selective $\beta_{1}$ receptor blocker used in treatment of several diseases of the cardiovascular system, especially hypertension. This drug is amongst the most widely prescribed drugs in the world, based on the aryloxypropranololamine backbone (Figure 1) [1-3]. Various methods have been developed for the determination of metoprolol including gas chromatography [4, 5], highperformance liquid chromatography (HPLC) with UV [6-8], fluorimetric [9, 10] and MS detection [11]. The main problems encountered using chromatographic methods are either the need for derivatisation or the need for time-consuming extraction procedures. Since these techniques need 
relatively expensive instrumentation and running costs, the use of simpler, faster and less expensive, but still sensitive, electrochemical techniques can be an interesting alternative.

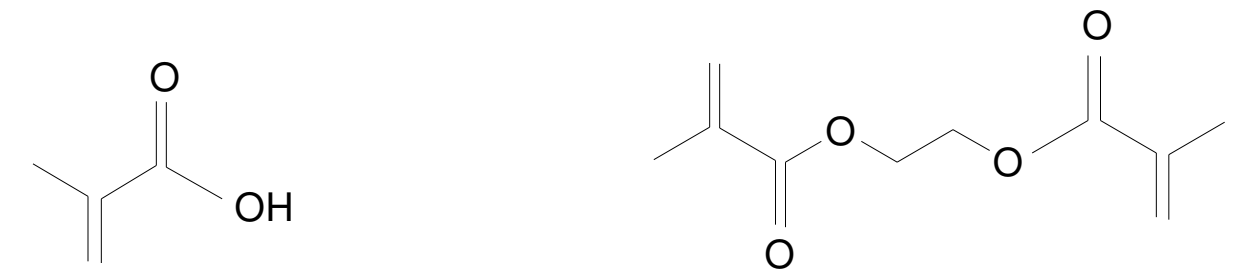

Methacrylic acid (MAA) Ethylene glycol dimethacrylate (EGDMA)

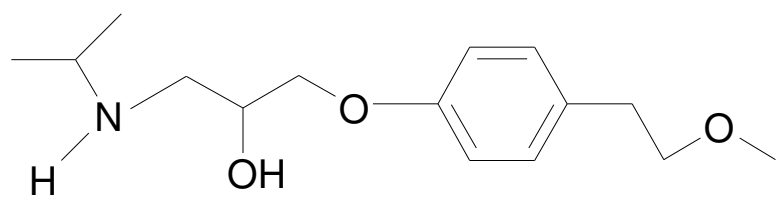

Metoprolol

Figure 1. Chemical structure of functional monomer (MAA), cross-linking monomer (EGDMA) and imprint molecule (Metoprolol).

Among the reported researches in the field of electrochemical methods for $\beta$-blockers [12-15], there are only a few papers that concern directly metoprolol [15] and nearly no article is found that reported for detection of metoprolol using MIP based ion-selective electrode. Generally, it can be mentioned that there are only a few reports dealing with potentiometric molecular sensors based on MIPs [16-23].

Molecular imprinting has been known as a polymerization technique to prepare synthetic polymers with recognition sites for given molecules [24]. Among the different methods available for the preparation of molecularly imprinted polymers (MIPs), the so-called non-covalent approach, which uses only non-covalent interactions between the template and the functional monomers, is probably the most flexible regarding the selection of the functional monomers and the possible template molecules. For these reasons, the non-covalent approach has been the most widely adopted [25]. The procedure for synthesizing an MIP is based on the chemical polymerization of a functional monomer and a crosslinking agent in the presence of a molecule used as a template. After removal of the imprinted molecule, an imprinted polymer is obtained. This polymer contains sites with a high affinity for the template molecule, due to their shapes and the arrangement of the functional groups of the monomer units. The imprinted polymers are used as antibody-like materials for high selectivity and sensitivity, owing to their long-term stability, chemical inertness and insolubility in water and most organic solvents [26]. 
The potentiometric electrochemical sensor for metoprolol was prepared from molecularly imprinted polymer (MIP) in this work. This study describes the construction and application of a coated graphite ion-selective electrode of metoprolol in aqueous medium using prepared MIP in the construction of electrode membrane.

The reemergence of ion-selective electrodes as a strong research direction in the field of potentiometric sensors is largely due to their improved mechanistic understanding [27]. Compared with other methods of trace analysis, potentiometry is an extremely inexpensive technique. Potentiometric sensors are known to only minimally perturb the sample, compared with most other analytical methods, and they should be especially well suited for integration into optimized fluidic and microfluidic systems for a variety of applications [28]. In the present work, we propose a MIP-based ion-selective electrode for metoprolol present in tablet, human urine and plasma by casting a membrane after dispersing metoprolol imprinted polymer particles in dioctylphthalate (DOP) and embedding in polyvinyl chloride (PVC) matrix.

\section{EXPERIMENTAL PART}

\subsection{Reagents and apparatus}

All chemicals were of analytical grades and all solutions were prepared in double distilled water. Metoprolol tartrate was obtained from SUN Pharmaceutical Industries LTD (Maharashtra, India). Methacrylic acid (MAA), ethylene glycol dimethacrylate (EGDMA), chloroform, acetic acid, acetonitrile, methanol, hydrochloric acid, trifluoroacetic acid (TFA) triethylamine, sodium chloride and the nitrate salts of all cations used (all from Merck), dibutyl phthalate (DBP), dioctyl phthalate (DOP), ortho-nitro phenyl octyl ether (o-NPOE), poly (vinyl chloride) (PVC) (with high relative molecular weight), oleic acid (OA) (all from Fluka), potassium tetrakis (p-chlorophenyl) borate (KTpClPB), sodium tetraphenyl borate (NaTPB) and 2, 2'-azobisisobutyronitrile (AIBN) (from Aldrich) were used as received.

All potentials were measured on digital Hioki 3200 multimeter vs. a Philips saturated calomel reference electrode (SCE) at $25.0 \pm 0.1^{\circ} \mathrm{C}$. The Fourier transform infrared (FTIR) spectra of nonimprinted and molecularly imprinted polymers were obtained using a Nexus870 Thermo Nicolet FTIR spectrometer. A Shimadzu-UV-1700 PC controlled double beam spectrophotometer equipped with quartz cell with a 1-cm path length was used for recording absorbances in the comparative study with pharmacopoeia method [29]. HPLC-comparative measurements were performed using a Perkin-Elmer 200 Series chromatographic workstation. A model MP225 Mettler-Toledo pH-meter was used for the pH adjustments.

Stock solution of metoprolol $\left(5.0 \times 10^{-2} \mathrm{M}\right)$ was prepared by dissolving an appropriate amount of metoprolol tartrate in bidistilled water. Other dilute solutions $\left(1.0 \times 10^{-2} \mathrm{M}-1.0 \times 10^{-8} \mathrm{M}\right)$ were prepared by serial dilution at constant ionic strength $(0.05 \mathrm{M} \mathrm{NaCl})$ and all $\mathrm{pHs}$ were adjusted with $\mathrm{HNO}_{3}$ or $\mathrm{NaOH}$. 


\subsection{Preparation of metoprolol MIP or non-imprinted (NIP) polymer particles}

The procedure for the synthesis of MIP and NIP polymers was as following procedure:

Briefly, to a three-necked round-bottom flask were added template (metoprolol tartrate; $0.25 \mathrm{mmol}$, or $0.171 \mathrm{~g}$ or metoprolol; $0.5 \mathrm{mmol}$; omit from the NIP), functional monomer (MAA; $2 \mathrm{mmol}$, or $0.17 \mathrm{~mL}$ ), cross-linker (EGDMA; $10 \mathrm{mmol}$, or $1.89 \mathrm{~mL}$ ) and initiator (AIBN; $0.25 \mathrm{mmol}$, or $0.042 \mathrm{~g}$ ) in chloroform $(20 \mathrm{~mL})$. The mixture was sparged with nitrogen for 10min to remove dissolved oxygen, which can inhibit free radical polymerization. The polymerization was allowed to continue in a water bath at $60^{\circ} \mathrm{C}$ for $18 \mathrm{~h}$. After polymerization, a hard polymer monolith was obtained, which was crushed and ground into a fine powder with a mortar and pestle. Soxhlet extraction was performed to remove the template with 70:30 (V/V) methanol: acetic acid overnight. Then, the polymer was washed several times with pure methanol to remove the acetic acid and facilitate drying. The dried polymer is ready for use.

\subsection{Electrode preparation}

The general procedure used to prepare the PVC membrane is similar to works reported by Prasada Rao [19, 20], Sales [18], Gupta [30], Al Attas [31, 32], Ganjali [33] and Shamsipur [34]. Exactly $60 \mathrm{mg}$ PVC was dissolved in $2.5 \mathrm{~mL}$ of THF. A $40 \mathrm{mg}$ of MIP or NIP particles were dispersed in $0.2 \mathrm{ml}$ of DOP and were added to the above solution and homogenized. Graphite electrodes ( $3 \mathrm{~mm}$ diameter and $10 \mathrm{~mm}$ long) were prepared from spectroscopic grade graphite. The electrode was polished with fine alumina slurries on a polishing cloth, sonicated in distilled water and dried in air. A shielded copper wire was glued to one end of the above graphite rod with epoxy resin, and the electrode was sealed into the end of a PVC tube. The polished electrode was dipped into the membrane solution, and the solvent was evaporated. A layer was formed on the graphite surface, and it was allowed to set for $3 \mathrm{hs}$. The electrode was finally conditioned for $18 \mathrm{hs}$ by soaking in a $1.0 \times 10^{-4} \mathrm{M}$ solution of metoprolol.

\subsection{Emf measurements}

The following cell assembly was used for measurements of all emfs:

SCE I Sample solution I MIP-based membrane I Graphite electrode

The coated electrode containing MIP was used as the measuring electrode in conjunction with a SCE and activity coefficients were calculated according to the Debye-Huckel equation:

$$
\log \gamma=\frac{-0.51 z^{2} \sqrt{\mu}}{1+\sqrt{\mu}}
$$


Where $\gamma$ is the activity coefficient, $\mu$ and $z$ are the ionic strength and charge of the ions, respectively.

\section{RESULTS AND DISCUSSION}

\subsection{Preparation and characterization of MIP}

In the beginning of this section it is noteworthy that, since, in preparation of many non-covalent MIPs a template: functional monomer: cross-linker molar ratio of about 1: 4: 20 has resulted in very suitable performance characteristics; this ratio was used for synthesis of metoprolol molecularly imprinted polymer in the present work [17, 19, 26, 35-42]. The most commonly used functional monomer is methacrylic acid (MAA). In addition to the strong ionic interactions that MAA can form with basic functional groups on the template, the carboxyl group on this monomer is an excellent hydrogen bond donor and acceptor [26]. The chemical environment and morphology of the MIP are greatly affected by the choice of cross-linking monomer, so that careful consideration must be given to its choice. The most commonly used cross-linker EGDMA has two acrylate groups that enable it to form more rigid polymers. This enhanced rigidity has been shown to lead to MIPs with higher capacities and selectivities [26]. For efficient template-monomer interactions, generally, aprotic organic solvents with low polarities are required. An MIP prepared in a solvent with such characteristic (e.g., chloroform) lead to an MIP will have binding sites with higher fidelity and the capacities will be increased [26]. With Regard to above statements we used MAA, EGDMA and chloroform as functional monomer, cross-linker and porogenic solvent, respectively in the synthesis procedure of MIP.

Control polymer and molecularly imprinted particles obtained using non-covalent imprinting protocol were subjected to characterization by FT-IR and binding batch static methods.

\subsubsection{FT-IR spectra}

The FT-IR spectra of control non-imprinted and molecularly imprinted polymer materials prepared using radical bulk polymerization are shown in Figure 2. Both polymers have similar IR spectra indicating the similarity in the backbone structure. In the IR spectra, the absorptions due to carboxyl OH stretch $\left(\sim 3500 \mathrm{~cm}^{-1}\right)$, carbonyl group stretch $\left(\sim 1730 \mathrm{~cm}^{-1}\right)$, C-O stretch $\left(\sim 1260 \mathrm{~cm}^{-1}\right)$ and C-H vibrations $\left(\sim 756, \sim 1390, \sim 1460\right.$, and $\left.\sim 2956 \mathrm{~cm}^{-1}\right)$ were observed. In addition to backbone similarity concluding, two important results were also acquired from spectra that are:

(1) Slight contrast of metoprolol tartrate and imprinted polymer FT-IR spectra proved that imprint molecule (metoprolol) has been sufficiently leached from MIP in the soxhlet extraction stage.

(2) This feature is clear that absorbances attributed to the $\mathrm{C}-\mathrm{H}$ stretch of methylene group $\left(\sim 2956 \mathrm{~cm}^{-1}\right)$, carbonyl group stretch $\left(\sim 1730 \mathrm{~cm}^{-1}\right)$, C-O stretch $\left(\sim 1260 \mathrm{~cm}^{-1}\right)$ and C-H bend of -CH2 $\left(\sim 1460 \mathrm{~cm}^{-1}\right)$ for the molecularly imprinted polymer are relatively stronger than for non-imprinted polymer. From this comparison it was found that presence of imprint molecule (metoprolol) causes incorporation of ethylene glycol dimethacrylate in the preparation of polymer to be increased. 


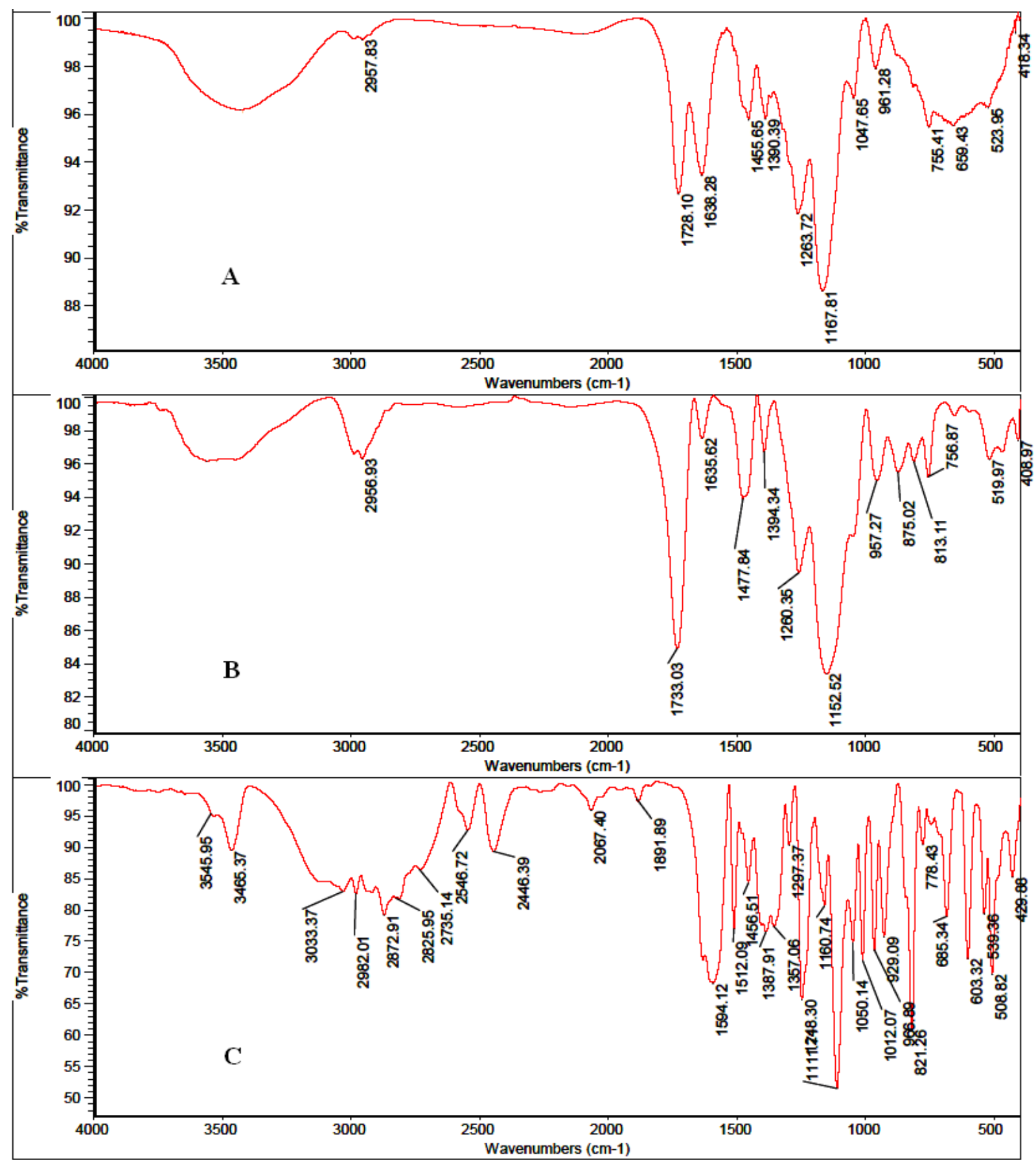

Figure 2. FT-IR spectra of NIP (A), MIP (B) and metoprolol tartrate (C) in the $400-4000 \mathrm{~cm}^{-1}$ range by $\mathrm{KBr}$ pellet method.

\subsubsection{Binding experiment by Batch static method}

Six portions of standard or sample solutions $(100 \mathrm{~mL})$ containing metoprolol $(0.3 \mathrm{mg})$ were individually transferred into $250 \mathrm{~mL}$ beakers, and the $\mathrm{pH}$ value was adjusted to 6.00 with $0.1 \mathrm{M}, \mathrm{HNO}_{3}$ 
or $\mathrm{NaOH}$. Then amounts of $50 \mathrm{mg}$ MIP adsorbent were added, and the mixtures were shaken vigorously for $30,60,90,120,150$ and $180 \mathrm{~min}$ to facilitate adsorption of the metoprolol onto the imprinted polymer particles. After the solutions were centrifuged, free concentration of metoprolol in the filtrate solutions were directly determined by spectrophotometry. It was found from resulted data that the time period of $150 \mathrm{~min}$ incubation is enough to achieve equilibrium. The amount of metoprolol bound to the polymer was calculated by subtracting the amount of free substrate from the initial amount of template. The same procedure was performed with NIP particles. The phase distribution ratio $\left(\mathrm{K}_{\mathrm{d}}\right)$ and adsorption capacity $(\mathrm{Q})$ were calculated using the following equations:

$$
\begin{aligned}
& K_{d}=\frac{C_{i}-C_{f}}{C_{f}} \times \frac{V}{W} \\
& Q=\frac{\left(C_{i}-C_{f}\right) V}{W}
\end{aligned}
$$

Where $C_{i}$ and $C_{f}$ represent the initial and equilibrium concentration of metoprolol in the aqueous phase $\left(\mathrm{mg} \mathrm{mL}^{-1}\right), \mathrm{W}$ is the weight of the polymer $(\mathrm{g})$ and $\mathrm{V}$ is the volume of the aqueous phase $(\mathrm{mL})$. Data from adsorption capacity studies were replaced in equations 1 and 2 and thus $\mathrm{K}_{\mathrm{d}}$ and $\mathrm{Q}$ respectively were achieved $307.78 \pm 17.75 \mathrm{~mL} \mathrm{~g}^{-1}$ and $0.8 \pm 0.04 \mathrm{mg} \mathrm{g}^{-1}$ for MIP and were obtained $36.58 \pm 2.94 \mathrm{~mL} \mathrm{~g}^{-1}$ and $0.114 \pm 0.01 \mathrm{mg} \mathrm{g}^{-1}$ for NIP. By evaluation of these data two important issues could be found:

(1) $\mathrm{K}_{\mathrm{d}}$ and Q quantities of NIP are negligible in comparison to MIP particles that connected to creation of shape-selective binding sites into three-dimensional polymeric network of MIP.

(2) Since NIP materials are lack of binding points, adsorption of metoprolol onto that is based on non-specific interactions, thus as seen from above data relative standard deviation (\%RSD) in the determination of $\mathrm{K}_{\mathrm{d}}$ and Q for MIP is obviously less than that of NIP.

\subsection{Optimal membrane composition}

In chemical sensors and biosensors, a chemical or physical signal is generated upon the binding of the analyte to the recognition element, a transducer then translates this signal into a quantifiable output signal. The same general principle applies if a molecularly imprinted polymer is used as the recognition element instead of a biomolecule [16]. The possibility of developing ion-selective electrodes for a few drugs and herbicides has recently opened up with the availability of MIP materials [17-23]. It is well known that MIPs have binding sites that are complementary in size and shape to the imprint molecule. In other words, a molecular memory is introduced into the polymer, which is capable of selectively rebinding the analyte. In this paper, the optimal conditions for the best performance of metoprolol-selective electrode based on a membrane of MIP have been investigated systematically. 
In the conventional potentiometric sensors for inorganics, it has been known that important features of the PVC membrane such as the nature and amount of ion recognizing material, solvent mediator (plasticizer) and especially, the nature of used additives significantly influence the sensitivity and selectivity of ion-selective electrodes [43, 44]. Thus, different aspects of membrane preparation based on synthesized imprinted polymer were optimized and the results are summarized in Table 1.

Table 1. Effect of membrane composition on MIP-based metoprolol electrode response

\begin{tabular}{cccccccccc}
\hline $\begin{array}{c}\text { Membran } \\
\text { e no. }\end{array}$ & $\begin{array}{c}\text { MIP } \\
(\mathrm{g})\end{array}$ & $\begin{array}{c}\text { PVC } \\
(\mathrm{g})\end{array}$ & $\begin{array}{c}\text { o-NPOE } \\
(\mathrm{mL})\end{array}$ & $\begin{array}{c}\mathrm{DBP} \\
(\mathrm{mL})\end{array}$ & $\begin{array}{c}\text { DOP } \\
(\mathrm{mL})\end{array}$ & $\begin{array}{c}\text { KTpClP } \\
\mathrm{B}(\mathrm{g})\end{array}$ & $\begin{array}{c}\text { NaTP } \\
\mathrm{B}(\mathrm{g})\end{array}$ & $\begin{array}{c}\text { OA } \\
(\mathrm{g})\end{array}$ & $\begin{array}{c}\text { Slope } \\
(\mathrm{mV} / \mathrm{decad} \\
\mathrm{e})\end{array}$ \\
\hline 1 & 0.03 & 0.06 & 0.2 & - & - & - & - & - & 19.8 \\
2 & 0.03 & 0.06 & - & 0.2 & - & - & - & - & 34.7 \\
3 & 0.03 & 0.06 & - & - & 0.2 & - & - & - & 49.2 \\
4 & 0.01 & 0.06 & - & - & 0.2 & - & - & - & 18.1 \\
5 & 0.02 & 0.06 & - & - & 0.2 & - & - & - & 35.9 \\
6 & 0.04 & 0.06 & - & - & 0.2 & - & - & - & 54.3 \\
7 & 0.05 & 0.06 & - & - & 0.2 & - & - & - & 41.5 \\
8 & 0.06 & 0.06 & - & - & 0.2 & - & - & - & Unstable \\
9 & 0.035 & 0.06 & - & - & 0.2 & - & - & - & 52.4 \\
10 & 0.045 & 0.06 & - & - & 0.2 & - & - & - & 55.1 \\
11 & 0.04 & 0.06 & - & - & 0.2 & 0.006 & - & - & 54.8 \\
12 & 0.04 & 0.06 & - & - & 0.2 & 0.012 & - & - & 55.9 \\
13 & 0.04 & 0.06 & - & - & 0.2 & - & 0.006 & - & 45.2 \\
14 & 0.04 & 0.06 & - & - & 0.2 & - & 0.012 & - & 45.7 \\
15 & 0.04 & 0.06 & - & - & 0.2 & - & - & 0.006 & 40.3 \\
16 & 0.04 & 0.06 & - & - & 0.2 & - & - & 0.012 & 40.6 \\
\hline
\end{tabular}

${ }^{*}$ Concentration range $=1.0 \times 10^{-7}$ to $1.0 \times 10^{-2} \mathrm{M} ; \mathrm{pH}$ of solutions $=6$

- Optimum composition

On the other hand, since in preparation of previous PVC-MIP membrane-selective electrodes a plasticizer amount of $\sim 0.2 \mathrm{~mL}$ has resulted in very suitable performance characteristics [19-22], this amount was kept constant in optimization of the ingredients of the proposed metoprolol-selective electrode (Table 1).

Since the nature of the plasticizer influence the dielectric constant of the membrane phase and the mobility of the attendant species [43], it is expected to play a fundamental role in determining the selective electrode characteristics. It is seen that among three different solvent mediators used, the use of $0.2 \mathrm{~mL}$ DOP in the presence of $30 \mathrm{mg}$ MIP (nos. 1-3, Table 1) provides better sensitivity, with a slope of $49.2 \pm 1 \mathrm{mV}$ decade $^{-1}$. The results indicate that the membrane with o-NPOE offered lower sensitivity in the range $1.0 \times 10^{-7} \mathrm{M}$ to $1.0 \times 10^{-2} \mathrm{M}$. By evaluation of these observations we found that the plasticizers having low dielectric constants, i.e. DOP $(\varepsilon=5.0)$ and DBP $(\varepsilon=8.5)$ give better response characteristics compared to o-NPOE with high dielectric constant of 24.0. This optimum response in the case of DOP solvent mediator is most likely that in addition to existence of shapeselective recognition binding points within the MIP, because of low dielectric constant of the 
membrane plasticized with DOP highly energetic ionic interaction can occur between carboxylic groups of binding sites and metoprolol is positively charged.

The influence of the quantities of MIP and PVC and MIP/PVC ratio in the membrane with 0.2 $\mathrm{mL}$ of DOP was investigated, and the results are shown in Table 1 (nos. 3-10). The sensitivity of electrode's response increases with increasing MIP content until a value of $45 \mathrm{mg}$ and MIP/PVC ratio up to 0.75 is reached. A further addition of MIP will, however, result in some decreased response of the electrode, most probably due to some inhomogeneities and possible saturation of the membrane [45].

It should be noted that, even though addition of the KTpClPB results in near response to additive free state but since the selectivity coefficients of the metoprolol membrane sensor (membranes 11, 12) was somehow larger than additive free electrode, thus finally, KTpClPB free membrane (no. 6) was selected for the other steps in this study (it sufficed to inspect $\mathrm{K}^{+}$and $\mathrm{Ca}^{2+}$ ions only, in the presence and absence of KTpCIPB).

\subsection{Concentration of conditioning solution}

The proposed membrane electrode was also examined with different concentrations of conditioning solution from $1.0 \times 10^{-3} \mathrm{M}$ to $1.0 \times 10^{-5} \mathrm{M}$. Functioning of the membrane sensor with solution of various metoprolol tartrate concentrations was found to cause no significant difference in the intercept of the resulting potential- $\log C_{\text {metoprolol }}$ plots but in the case of $1.0 \times 10^{-4} \mathrm{M}$ more stable responses were obtained compared to $1.0 \times 10^{-3} \mathrm{M}$ and $1.0 \times 10^{-5} \mathrm{M}$. Thus a $1.0 \times 10^{-4} \mathrm{M}$ concentration of the conditioning solution is quite appropriate for smooth functioning of the membrane electrode system. It should be noted that the optimum equilibrium time for the membrane sensor was found to be $18 \mathrm{~h}$, after which stable potentials are generated in contact with metoprolol solutions.

\subsection{Response time and reversibility}

In this study, the practical response time or the average time required for the metoprolol sensor to reach $90 \%$ of the maximum potential after immersion of metoprolol solution having a 10-fold difference in concentration, was recorded (Figure 3, two isolated assessing with jumps of $5.0 \times 10^{-5} \mathrm{M}$ to $5.0 \times 10^{-4} \mathrm{M}$ and $5.0 \times 10^{-4} \mathrm{M}$ to $5.0 \times 10^{-3} \mathrm{M}$ ) [43]. To evaluate the reversibility of the electrode, the measurements were performed in the sequence of high-to-low sample concentrations and the results are shown in Figure 4. Here it is seen that the potentiometric response of the sensor is reversible, although the time needed to reach the equilibrium values were longer than that for the high-to-low sample concentration procedure. It is well documented that, in the case of high-to-low concentrations, the time needed to attain a stable potential is some 100 times larger than that required for the case of low-to-high concentrations (for a 10 times change in the concentration) [43]. 


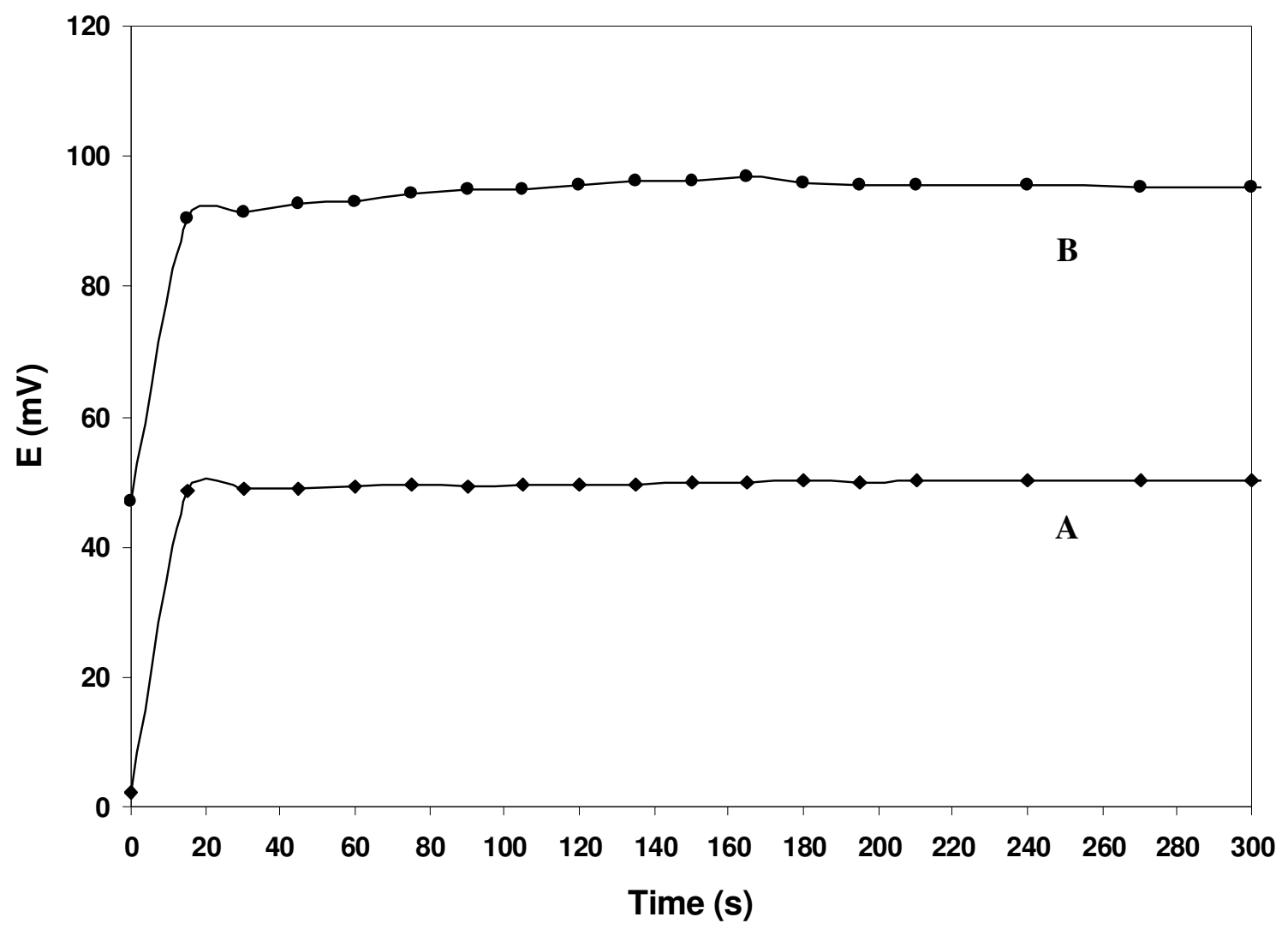

Figure 3. Response time of metoprolol selective electrode with two isolated jumps in concentration; (A) $5.0 \times 10^{-5} \mathrm{M}$ to $5.0 \times 10^{-4} \mathrm{M}$, (B) $5.0 \times 10^{-4} \mathrm{M}$ to $5.0 \times 10^{-3} \mathrm{M}$.

\subsection{Effect of $p H$}

The $\mathrm{pH}$ dependence of the membrane sensor was tested over the $\mathrm{pH}$ range $2.0-12.0$ at $1.0 \times 10^{-4}$ $\mathrm{M}$ and $1.0 \times 10^{-5} \mathrm{M}$ metoprolol concentrations (Figure 5). Adjustments of $\mathrm{pH}$ were made with nitric acid or sodium hydroxide solutions. As is seen from Figure 5, potentials stay constant from $\mathrm{pH} 3.5$ to 10.5, beyond which potential drifts are observed. Thus, this range will be taken as the working $\mathrm{pH}$ range of the proposed sensor. This behavior of prepared membrane can be interpreted as follows:

(1) According to some literatures the $\mathrm{pK}_{\mathrm{a}}$ of metoprolol is about 9.5 [46-48], i.e. at alkaline $\mathrm{pHs}$ it becomes increasingly dissociated and is in non-cationic form. Thus the observation of decrease in potentials was obvious at this $\mathrm{pH}$ range.

(2) Below $\mathrm{pH} 3.5$, membrane maybe response to $\mathrm{H}^{+}$and for this reason increase in potentials was observed. 


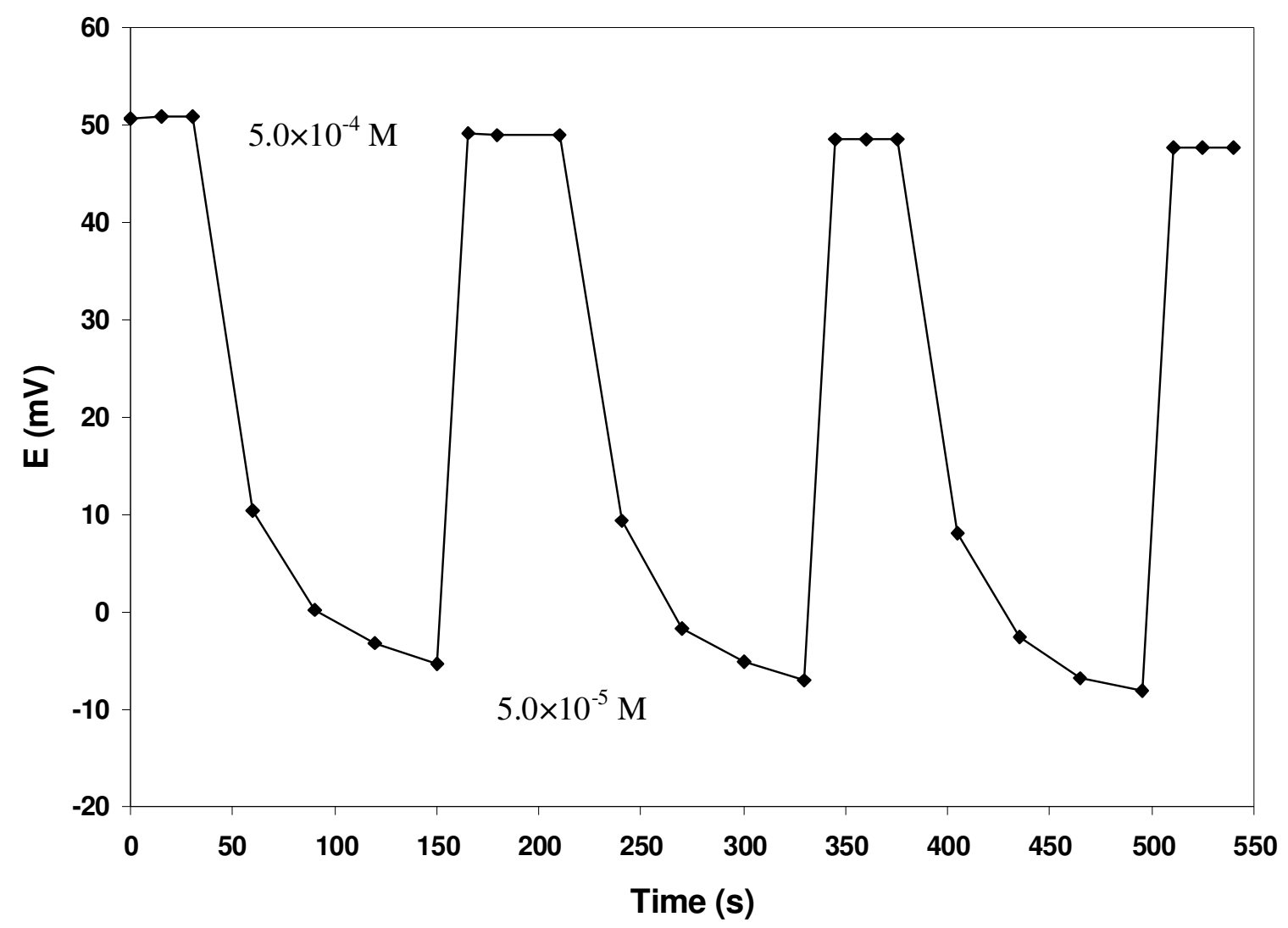

Figure 4. Reversibility of the metoprolol selective electrode in several high-to-low sample cycles.

\subsection{Calibration curve}

After optimization of membrane composition, we replaced MIP with the NIP at same amount (40 mg) and compared the electrode performance in the presence of both these polymers. In other words by this means, to confirm the efficiency of the MIP, the potentiometric response of the nonimprinted polymer modified sensor was also examined. Typical potential response curves of the sensors based on NIP and MIP to metoprolol in the concentration range of $5.0 \times 10^{-8} \mathrm{M}$ to $5.0 \times 10^{-2} \mathrm{M}$ are shown in Figure 6. As seen, a specific response to metoprolol could be observed with MIP but not with NIP, suggesting that the molecular imprinting is more effective in metoprolol sensing than to the non-imprinted polymer. The slope of $\sim 23$ in the range $5.0 \times 10^{-6} \mathrm{M}$ to $1.0 \times 10^{-3} \mathrm{M}$ for NIP-based membrane is most probably due to carboxyl groups on the surface of the polymer which can have nonspecific interactions with the cationic species present (e.g. metoprolol).

The emf response of the MIP-based membrane at varying concentration of metoprolol (Figure 6) indicates a rectilinear range from $2.0 \times 10^{-7} \mathrm{M}$ to $8.0 \times 10^{-3} \mathrm{M}$. The slopes of the calibration curves were $55.4 \pm 1 \mathrm{mV}$ per decade of metoprolol concentration. The limit of detection, as determined from the intersection of the two extrapolated segments of the calibration graph, was $1.26 \times 10^{-7} \mathrm{M}$. The electrodes exhibit a stable potential response and almost unchanged metoprolol selectivity for at least 6 months. 


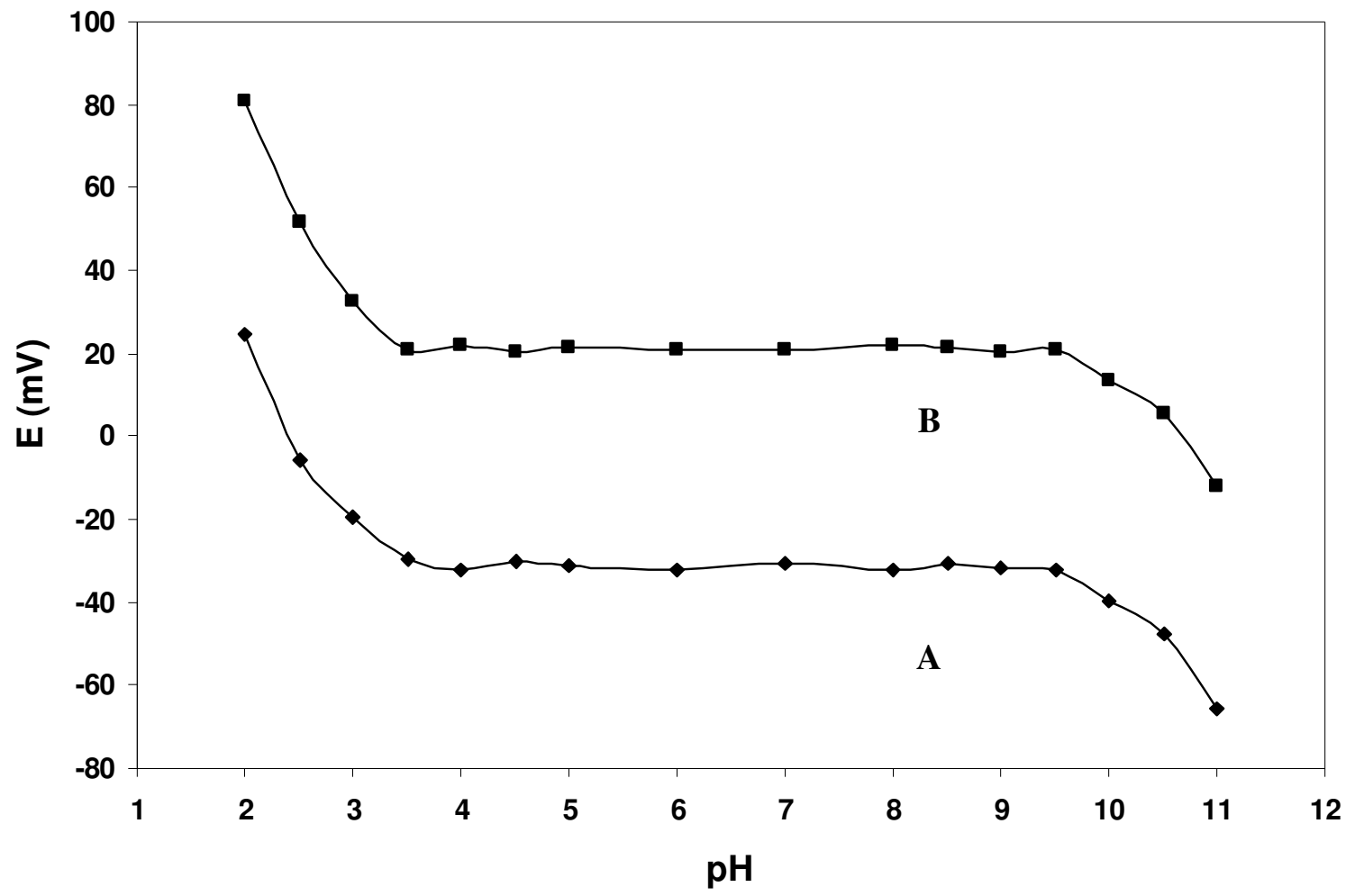

Figure 5. Effect of $\mathrm{pH}$ of test solution on the potential response of the metoprolol selective sensor at (A) $1.0 \times 10^{-5} \mathrm{M}$ and (B) $1.0 \times 10^{-4} \mathrm{M}$ metoprolol concentrations.

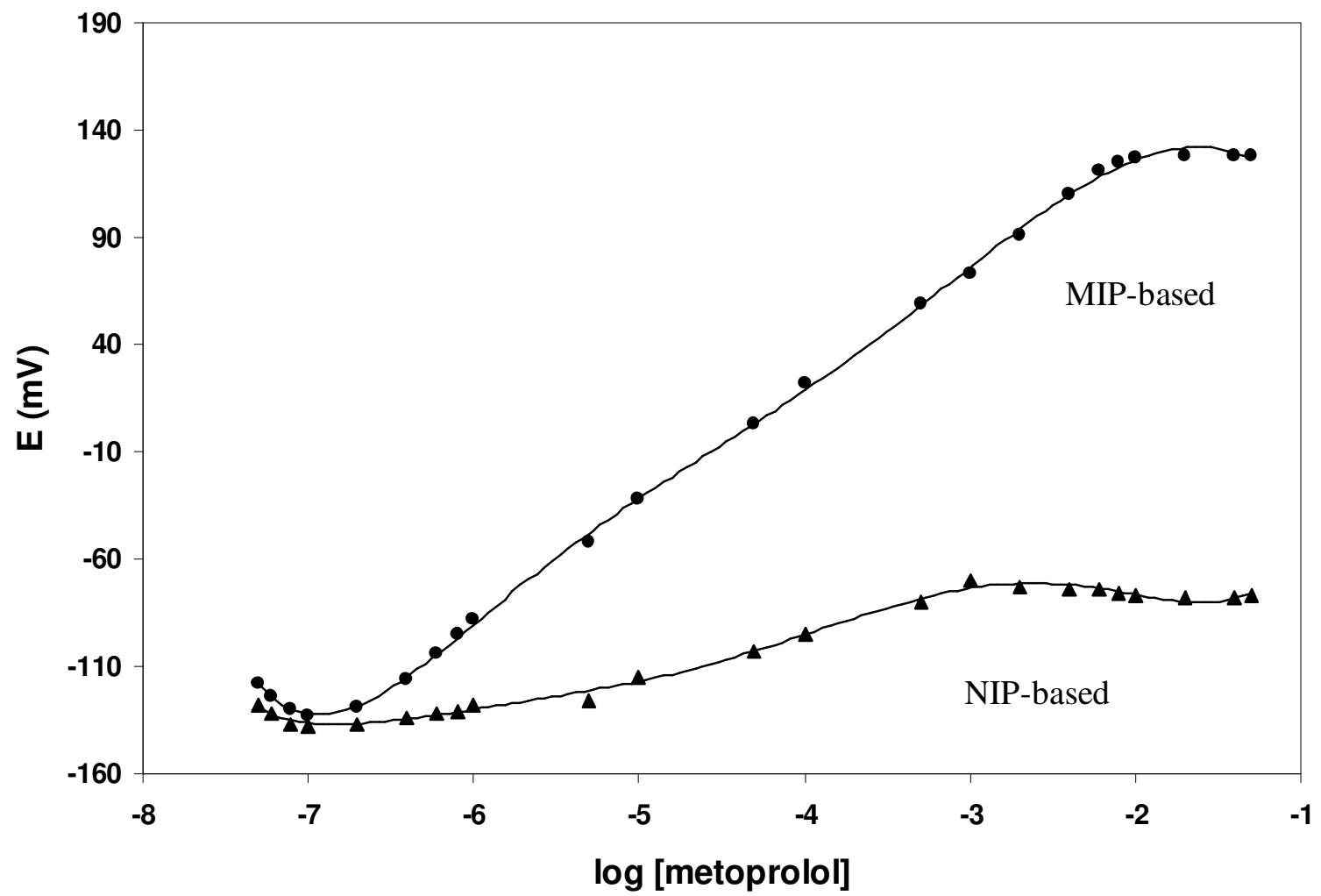

Figure 6. Calibration plot for the proposed metoprolol selective electrode with optimized membrane composition based on MIP and NIP particles. 


\subsection{Potentiometric selectivity}

The influence of interfering ions on the response behavior of ion-selective membrane electrodes is usually described in terms of selectivity coefficients. The potentiometric selectivity coefficients, $K_{\text {Met., } J}^{\text {Pot. }}$ of the NIP and MIP-membrane sensor were evaluated by the separate solutions method [31-33, 49, 50]. As seen from Table 2, the selectivity coefficients obtained for the examined species indicated that most of these compounds do not disturb the functioning of the metoprololselective electrode significantly.

Table 2. Selectivity coefficient values ( $K_{\text {Met.,J }}^{\text {Pot. }}$ ) of proposed electrode based on the MIP (I) and NIP (II) particles, respectively

\begin{tabular}{|c|c|c|c|c|c|}
\hline \multirow{2}{*}{$\begin{array}{l}\text { Interferent, } \\
\mathrm{J}\end{array}$} & \multicolumn{2}{|c|}{$K_{\text {Met. }, J}^{\text {Pot. }}$} & \multirow{2}{*}{$\begin{array}{l}\text { Interferent, } \\
\mathrm{J}\end{array}$} & \multicolumn{2}{|c|}{$K_{\text {Met. }, J}^{\text {Pot. }}$} \\
\hline & I & II & & I & II \\
\hline Urea & $3.6 \times 10^{-5}$ & $7.7 \times 10^{-4}$ & $\mathrm{~Pb}^{2+}$ & $3.4 \times 10^{-4}$ & $3.6 \times 10^{-3}$ \\
\hline $\begin{array}{c}\text { Benzoic } \\
\text { acid }\end{array}$ & $2.7 \times 10^{-2}$ & $8.3 \times 10^{-2}$ & $\mathrm{Cu}^{2+}$ & $9.9 \times 10^{-5}$ & $4.7 \times 10^{-4}$ \\
\hline $\begin{array}{l}\text { Oxalic } \\
\text { acid }\end{array}$ & $2.1 \times 10^{-1}$ & $9.9 \times 10^{-1}$ & $\mathrm{Ni}^{2+}$ & $2.2 \times 10^{-3}$ & $7.1 \times 10^{-3}$ \\
\hline Glucose & $6.9 \times 10^{-6}$ & $2.3 \times 10^{-4}$ & $\mathrm{Zn}^{2+}$ & $1.1 \times 10^{-3}$ & $5.2 \times 10^{-3}$ \\
\hline $\mathrm{Na}^{+}$ & $9.5 \times 10^{-4}$ & $1.1 \times 10^{-3}$ & & & \\
\hline $\mathrm{K}^{+}$ & $5.1 \times 10^{-4}$ & $4.1 \times 10^{-4}$ & & & \\
\hline $\mathrm{NH}_{4}^{+}$ & $7.5 \times 10^{-4}$ & $8.5 \times 10^{-4}$ & & & \\
\hline $\mathrm{Mg}^{2+}$ & $8.3 \times 10^{-5}$ & $1.3 \times 10^{-4}$ & & & \\
\hline $\mathrm{Ca}^{2+}$ & $1.8 \times 10^{-4}$ & $2.9 \times 10^{-4}$ & & & \\
\hline $\mathrm{Ba}^{2+}$ & $3.2 \times 10^{-5}$ & $5.1 \times 10^{-5}$ & & & \\
\hline
\end{tabular}

\section{PRELIMINARY APPLICATIONS}

\subsection{Potentiometric titration}

It should be noted that the metoprolol-selective membrane electrode introduced could not only be used for the direct determination of the metoprolol ions, but also it may have potential applications in a variety of fields. We successfully applied the MIP-based electrode as an indicator in the potentiometric titration of $25 \mathrm{~mL}$ of $0.005 \mathrm{M}$ metoprolol against $0.1 \mathrm{M}$ sodium tetraphenyl borate solution, and the resulting titration curve is shown in Figure 7. As seen, the amount of metoprolol in solution can be determined with the electrode.

\subsection{Determination of metoprolol tartrate in metoral ${ }^{\circledR}$ tablet}

It should be noted that we successfully applied the introduced metoprolol-selective membrane electrode for the direct determination of metoprolol tartrate in the metoral ${ }^{\circledR}$ tablet which was composed 
of metoprolol tartrate (50 mg per tablet) and some common excipients, bought from local pharmaceutical shop. The number of 10 tablets was finely ground, homogenized and a portion of the powder $(0.1812 \mathrm{~g}$, average tablet mass) was weighed accurately, transferred into a $500 \mathrm{~mL}$ flask and diluted to scale with water. The mixture was sonicated for at least $15 \mathrm{~min}$ to aid dissolution and then filtered. A $10 \mathrm{~mL}$ of the filtrate was diluted further to $50 \mathrm{~mL}$ with water so that the concentration of metoprolol in the final solution was within the working range, and then analyzed by the proposed MIP electrode. The resulted data from introduced potentiometric determination and their satisfactory agreements with both comparative pharmacopoeia method [29] and HPLC analysis [51] are shown in Table 3. HPLC studies in this and next part were carried out on C18 column. The mobile phase consisted of acetonitrile: methanol: acetic acid (\%0.5): triethylamine (56:18:26: 0.1, v/v) at a flow rate of $1.0 \mathrm{~mL} \mathrm{~min}^{-1}$ [51]. This HPLC system was equilibrated for approximately $30 \mathrm{~min}$ at same flow rate before analysis commenced. The injection volume was $20 \mu \mathrm{L}$ manually with a $100 \mu \mathrm{L}$ syringe and UV detection wavelength was $225 \mathrm{~nm}$. Chromatography was performed at ambient temperature and each analysis was repeated for three times.

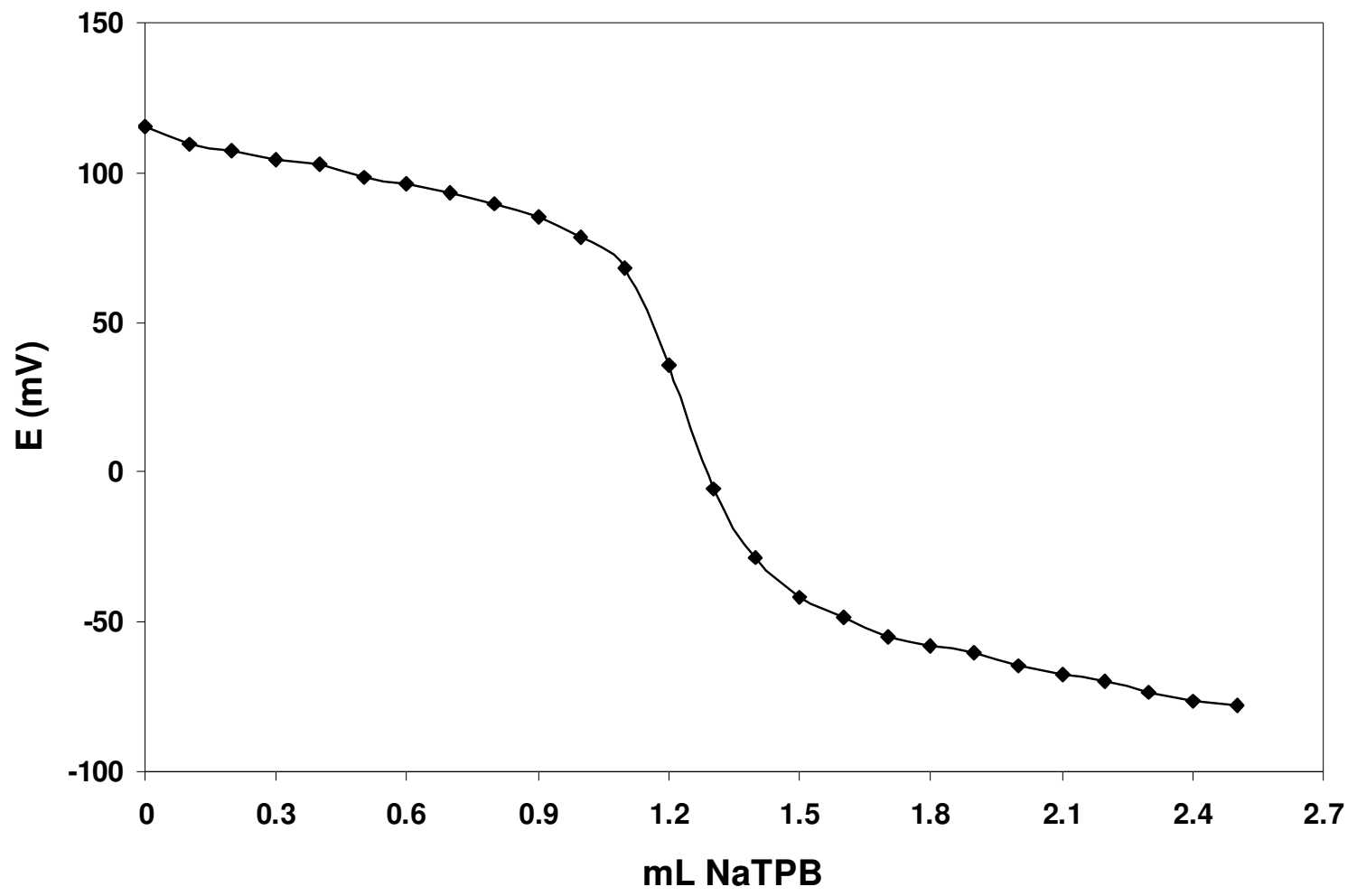

Fig. 7. Potentiometric titration curve of $25 \mathrm{~mL}$ of $0.005 \mathrm{M}$ metoprolol solution with $0.1 \mathrm{M} \mathrm{NaTPB}$, using the proposed sensor as an indicator electrode.

\subsection{Recoveries of spiked metoprolol in human urine and plasma samples}

The high degree of metoprolol selectivity exhibited by the membrane electrode makes it potentially useful for monitoring concentration level of metoprolol in real samples. In this regard, 
experiments were performed to determine the feasibility of using the electrode to measure metoprolol in human urine and plasma samples.

Blood samples $(5 \mathrm{~mL})$ were collected in heparin-containing tubes, protected from light and kept at $4^{\circ} \mathrm{C}$. Plasma was obtained after blood centrifugation at $1800 \mathrm{~g}$ for $5 \mathrm{~min}$ and was diluted ten times with water before potentiometric study. Urine sample $(10 \mathrm{~mL})$ was deproteinated with TFA (100 $\mu \mathrm{L}$ ), vortexed for $3 \mathrm{~min}$, and centrifuged for $5 \mathrm{~min}$ at $1500 \mathrm{~g}$. This treated sample was diluted 100 times with water prior to potentiometric proposed method and the results of the recovery studies summarized in Table 4 were found to be in satisfactory agreement with that determined by HPLC method. Excellent recovery was observed indicating that the constituents of the two performed samples do not interfere in any way with the detection of metoprolol.

Table 3. Determination of metoprolol tartrate in metoral ${ }^{\circledR}$ tablet

\begin{tabular}{cccc}
\hline & & Method & \\
\cline { 2 - 4 } & Proposed method & HPLC & Pharmacopoeia method \\
\hline $\begin{array}{c}\text { Content } \\
\text { (mg/tablet) }\end{array}$ & $49.11(3.57)$ & $48.70(1.81)$ & $48.11(2.92)$ \\
\hline
\end{tabular}

${ }^{*}$ Average of three measurements with R.S.D.\% in parenthesis

Table 4. Recoveries of spiked metoprolol in human urine and plasma samples

\begin{tabular}{cccc}
\hline & & \multicolumn{2}{c}{ Recovery $^{*}(\%)$} \\
\hline Sample & $\begin{array}{c}\text { Added metoprolol } \\
(\mathrm{mg})\end{array}$ & Proposed method & HPLC \\
\cline { 3 - 3 } Urine & 0.15 & $101.58(3.77)$ & $102.83(2.25)$ \\
Plasma & 0.15 & $102.18(4.13)$ & $103.91(2.12)$ \\
\hline
\end{tabular}

${ }^{*}$ Average of three measurements with R.S.D.\% in parenthesis

- Sample volumes for proposed method were $50 \mathrm{~mL}$.

\section{CONCLUSIONS}

The graphite-coated membrane electrode, prepared with molecularly imprinted polymer under optimal PVC-membrane ingredients, revealed a near nernstian response over a wide metoprolol 
concentration range, fast response time and selectivity over a large number of metal ions. The analytical applicability of proposed sensor was checked by the determination and recovery of metoprolol in tablets, human urine and plasma samples.

\section{ACKNOWLEDGEMENTS}

The Islamic Azad University, Science \& Research Branch, Laboratory Research Complex, Analytical Chemistry laboratory supported this work.

\section{References}

1. K.V. Gowda, U. Mandal, P.S. Selvan, W.D.S. Solomon, A. hosha, A.K. Sarkar, S. Agarwal, T.N. Raob, T.K. Pal, J. Chromatogr. B, 858 (2007) 13

2. H. Liu, J. Ren, Y. Hao, H. Ding, P. He, Y. Fang, J. Pharm. Biomed., 42 (2006) 384

3. J. Fang, H.A. Semple, J. Song, J. Chromatogr. B, 809 (2004) 9

4. O. Gyllenhaal, K.J. Hoffmann, J. Chromatogr., 309 (1984) 317

5. C. D. Kinney, J. Chromatogr. B, 225 (1981) 213

6. V.G. Dongre, S.B. Shah, P.P. Karmuse, M. Phadke, V.K. Jadhav, J. Pharm. Biomed., 46 (2008) 583

7. H.K. Lim, P.T. Linh, C.H. Hong, K.H. Kim, J.S. Kang, J. Chromatogr. B, 755 (2001) 259

8. M.A. El-Ries, F.M. Abou Attia, S.A. Ibrahim, J. Pharm. Biomed., 24 (2000) 179

9. P.M. Cerqueira, V.B. Boralli, E.B. Coelho, N.P. Lopes, L.F.L. Guimaraes, P.S. Bonato, V.L. Lanchote, J. Chromatogr. B, 783 (2003) 433

10. K.H. Kim, H.J. Kim, J.S. Kang, W. Mar, J. Pharm. Biomed., 22 (2000) 377

11. A.K. Sarkar, D. Ghosh, A. Das, P.S. Selvan, K.V. Gowda, U. Mandal, A. Bose, S. Agarwal, U. Bhaumik, T.K. Pal, J. Chromatogr. B, 873 (2008) 77

12. M. Arvand, M. Vejdani, M. Moghimi, Desalination, 225 (2008) 176

13. V. Martinez, M.I. Maguregui, R.M. Jimenez, R.M. Alonso, J. Pharm. Biomed., 23 (2000) 459

14. A. Arranz, I. Dolara, S.F. de Betono, J.M. Moreda, A. Cid, J.F. Arranz, Anal. Chim. Acta, 389 (1999) 225

15. S.S.M. Hassan, M.M. Abou-Sekkina, M.A. El-Ries, A.A. Wassel, J. Pharm. Biomed., 32 (2003) 175

16. T.P. Rao, R. Kala, Talanta, 76 (2008) 485

17. M. Javanbakht, S. Eynollahifard, A. Mohammadi, M. Abdouss, M.R. Ganjali, P. Norouzi, L. Safaraliee, Anal. Chim. Acta, 612 (2008) 65

18. A.H. Kamel, F.T.C. Moreira, S.A.A. Almeida, M.G.F. Sales, Electroanalysis, 20 (2008) 194

19. K. Prasad, K.P. Prathish, J.M. Gladis, G.R.K. Naidu, T.P. Rao, Sens. Actuators B, 123 (2007) 65

20. K.P. Prathish, K. Prasad, T.P. Rao, M.V.S. Suryanarayana, Talanta, 71 (2007) 1976

21. V. Vishnuvardhan, K.P. Prathish, G.R.K. Naidu, T.P. Rao, Electrochim. Acta, 52 (2007) 6922

22. S. Sadeghi, F. Fathi, J. Abbasifar, Sens. Actuators B, 122 (2007) 158

23. G. D’Agostino, G. Alberti, R. Biesuz, M. Pesavento, Biosens. Bioelectron., 22 (2006) 145

24. K. Haupt, K. Mosbach, Chem. Rev., 100 (2000) 2495

25. A.G. Mayes, M.J. Whitcombe, Adv. Drug Deliver. Rev., 57 (2005) 1742

26. M. Yan, O. Ramstrom, Molecularly Imprinted Materials: Science and Technology, Marcel Dekker, New York (2005)

27. E. Bakker, M. Telting-Diaz, Anal. Chem., 74 (2002) 2781

28. E. Bakker, E. Pretsch, Anal. Chem., 74 (2002) 420A

29. British Pharmacopoeia Commission, British Pharmacopoeia, Stationery Office, London (2009) 9420 
30. V.K. Gupta, R.N. Goyal, R.A. Sharma, Int. J. Electrochem. Sci., 4 (2009) 156

31. A.S. Al Attas, Int. J. Electrochem. Sci., 4 (2009) 9

32. A.S. Al Attas, Int. J. Electrochem. Sci., 4 (2009) 20

33. M.R. Ganjali, R. Nematiı, F. Faridbod, P. Norouzi1, F. Darviche, Int. J. Electrochem. Sci., 3 (2008) 1288

34. M. Shamsipur, F. Mizani, K. Alizadeh, M.F. Mousavi, V. Lippolis, A. Garau, C. Caltagirone, Sens. Actuators B, 130 (2008) 300

35. A.R. Koohpaei, S.J. Shahtaheri, M.R. Ganjali, A. Rahimiforushani, F. Golbabaei, Talanta, 75 (2008) 978

36. Z. Sun, W. Schussler, M. Sengl, R. Niessner, D. Knopp, Anal. Chim. Acta, 620 (2008) 73

37. F.H. Chapuis, J.U. Mullot, G. Tuffal, M.C. Hennion, V. Pichon, J. Chromatogr. A, 1196-1197 (2008) 73

38. S.Y. Feng, E.P.C. Lai, E.D. Zlotorzynska, S. Sadeghi, J. Chromatogr. A, 1027 (2004) 155

39. A. Beltran, E. Caro, R.M. Marce, P.A.G. Cormack, D.C. Sherrington, F. Borrull, Anal. Chim. Acta, 597 (2007) 6

40. F. Breton, R. Rouillon, E.V. Piletska, K. Karim, A. Guerreiro, I. Chianella, S.A. Piletsky, Biosens. Bioelectron., 22 (2007) 1948

41. C. Baggiani, P. Baravalle, G. Giraudi, C. Tozzi, J. Chromatogr. A, 1141 (2007) 158

42. F. Chapuis, V. Pichon, F. Lanza, B. Sellergren, M.C. Hennion, J. Chromatogr. B, 804 (2004) 93

43. E. Bakker, Ph. Buhlmann, E. Pretsch, Chem. Rev., 97 (1997) 3083

44. T. Rosatzin, E. Bakker, K. Suzuki, W. Simon, Anal. Chim. Acta, 280 (1993) 197

45. K.C. Gupta, M.J. D’Arc, Anal. Chim. Acta, 437 (2001) 199

46. M. Bedner, W.A. MacCrehan, Chemosphere, 65 (2006) 2130

47. Z.S. Teksin, K. Hom, A. Balakrishnan, J.E. Polli, J. Control. Release, 116 (2006) 50

48. A. Detroyer, Y.V. Heyden, S. Carda-Broch, M.C. Garcia-Alvarez-Coque, D.L. Massart, J. Chromatogr. A, 912 (2001) 211

49. E. Bakker, E. Pretsch, Ph. Buhlmann, Anal. Chem., 72 (2000) 1127

50. Y. Umezawa, Ph. Buhlmann, K. Umezawa, K. Tohda, Sh. Amemiya, Pure Appl. Chem., 72 (2000) 1851

51. R.K.V. Konna, M.E. B, K.E.V. Nagoji, S.S. Rao, Indian J. Pharm. Sci., 65 (2003) 204

(C) 2010 by ESG (www.electrochemsci.org) 